\title{
Study of the Variation of Chromium Oxide and Iron in Oxide Layer by XPS in DSS 2205 with Higher and Lower Chromium Content Due to Ageing for 7000 Hours at $300^{\circ} \mathrm{C}$
}

\author{
João Roberto Sartori Moreno*, Carlos Elias da Silva Junior
}

Federal Technological University of Paraná, UTFPR, Campus Cornélio Procópio, Avenida Alberto Carazzai, Cornélio Procópio/PR, Brasil

\begin{abstract}
The surface oxidation of DSS 2205 duplex stainless steel was studied by X-ray photoelectron spectroscopy (XPS), for two different techniques witch were used to produce thin oxide layers on polished for measuring the concentration of oxide depends on the sputtering profile these duplex stainless steel samples. The experiments were performed in the temperature of $300^{\circ} \mathrm{C}$ with aging at 7000 hours e with growth of films obtained voltammetric curves (potentiostatically) of the samples in sulfuric acid $\left(\mathrm{H}_{2} \mathrm{SO}_{4}-0.1 \mathrm{M}\right.$ saturated) at low potential. The compositions of the modified oxidized surfaces were determined from the XPS survey scans, and the chemistry of selected elements from the higher-energy-resolution scans of the appropriate peaks. Various Iron/Chromium oxidized layers and various oxide thicknesses were observed and correlated with the temperature. It was found that all the techniques produced oxide layers with various traces of metallic components and with the maximum concentration of chromium oxide and iron oxide in layers close to the oxide layer/metal interface. Therefore this study showed results about the behavior of the DSS 2205 with higher and lower Cr content and that the annealing at $300^{\circ} \mathrm{C}$ for longer times $(7000 \mathrm{~h})$ promotes the enrichment of iron oxide, and consequently the decrease in the chromium oxide content, in the oxide surface of both the DSS 2205.
\end{abstract}

Keywords Sputtering profile, Duplex stainless steel, XPS, Chromium oxide, Iron oxide, Voltammetric curves

\section{Introduction}

The use of the duplex stainless steel has been highlighted with respect to other types of stainless steels because of their good mechanical properties and corrosion resistance.

However, when the duplex stainless steel is aged at low temperatures (around $300^{\circ} \mathrm{C}$ ), there is a significant degradation of their mechanical properties and their resistance to corrosion, due to the precipitation of phases, usually rich in chromium, generating impoverished regions of this element. In the case of Fe-Cr-Ni duplex stainless steels particularly, a passive state is obtained due to formation of surface oxide films.

The oxidation and corrosion resistance of stainless steel duplex has already been the subject of many studies. The corrosion resistance of stainless steel is known to be based on the $\mathrm{Cr}_{2} \mathrm{O}_{3}$ chromium oxide at the surface that is considered to act as a protective layer against corrosion due to its low diffusion constants for oxygen and metal ions according to

* Corresponding author:

joaosartori@utfpr.edu.br (João Roberto Sartori Moreno)

Published online at http://journal.sapub.org/materials

Copyright (C) 2014 Scientific \& Academic Publishing. All Rights Reserved

\section{ASTEMAN, H et.all (2004).}

The oxide layer formed on stainless-steel surfaces is usually not uniform in terms of the depth. Double or even triple layers can be formed on the surface, depending on the alloy composition, on the oxidizing conditions (oxidizing atmosphere, time, and temperature), and also on the different duplex stainless-steel iron phases as reported

Oxide films may theoretically consist of various iron and chromium oxides as well as their mixtures. Several authors have studied the formation of thin oxide layers on stainless steels, being oxidized in air or oxygen at various pressures and various temperatures second 2.DONIK, Č. et.all (2009) and VESEL, A. et.all (2007).

The oxidation in air showed that at most temperatures a duplex oxide layer was formed; the outer layer, $\alpha-\mathrm{Fe}_{2} \mathrm{O}_{3}$, was formed on the top of the inner oxide layer, an iron-chromium oxide as 1.DONIK, C. et.all. (2009).

The aim of the present study was to examine the initial phases of oxide growth on the 2205 duplex stainless steels as a function of temperatures up to $300^{\circ} \mathrm{C}$ too as 1 .DONIK, C. et. all. (2009).

The oxide layers were produced by the controlled exposure of polished duplex stainless-steel samples to oxygen atoms. X-ray photoelectron spectroscopy (XPS) was 
applied to measure the depth distributions of the oxide films formed on the surface by the sputter depth profiling.

To our knowledge, this is the first report on the depth distribution of oxide-layer compositions on DSS 2205 with higher and lower $\mathrm{Cr}$ content for the conditions specified in this paper.

\subsection{Experimental Procedures}

The samples used in this investigation were obtained from a hot rolled DSS whose composition is given in table 1, and then solubilized at $1250^{\circ} \mathrm{C}$ and then aged for $7000 \mathrm{~h}$ at $300^{\circ} \mathrm{C}$.

To evaluate growth models of films obtained voltammetric curves (potentiostatically) of the samples in sulfuric acid $\left(\mathrm{H}_{2} \mathrm{SO}_{4}-0.1 \mathrm{M}\right.$ saturated $)$ at low potential, specifically the first transition peak active-passive $(-300 \mathrm{mV})$ region, while the samples were also prepared the previously mentioned.

Immersion tests and surface analysis by XPS were conducted intending to quantify the depletion in the corrosion resistance and identify the oxides presented in the surface oxide layer second GRANROTH, S. et.all. (2011). X-Ray Photoelectron Spectroscopy (XPS) was used to analyse the surface oxide layer specially prepared after anodic polarization in the passive region in acid media. The samples were analyzed after preparation with the aid of a photoelectron spectroscope excited by the X-ray KRATOS ANALYTICAL model HS XSAM under ultra-vacuum (in the range of $\left.5 \times 10^{-7} \mathrm{PA}\right)$. Exciter was used as the radiation source $\mathrm{K}_{\alpha} \mathrm{Mg}\left(\mathrm{h}_{\mathrm{v}}=1253.6 \mathrm{eV}\right)$ with a power of $130 \mathrm{~W}$ (issue of $10 \mathrm{~mA}$ and voltage of $13 \mathrm{kV}$ ). The background was subtracted by the Shirley method as related KOCIJAN, A. et.all. (2009) and the peaks were fitted using both Gaussian and mixed Gaussian/Lorentzian functions.

The adjustment of the peaks was done using equipment available in "software". It was promoted by ion bombardment cleaning to preserve the film grown potentiostatically.

\section{Results and Discussion}

The results showed that the samples heat treated (solubilized) at $1250^{\circ} \mathrm{C}$ during 1 hour and quenched in water at $25^{\circ} \mathrm{C}$, presented approximate the ferrite-austenite percentage to $50: 50 \%$, but with content of chromium and iron in the phase ferrite and austenite as showed table 2 . The presence of more than one $\mathrm{Cr}$ rich phase retards the kinetics of precipitation and the effects were not noticed at $300^{\circ} \mathrm{C}$.

As can be seem, in both phases austenite in ferritic matrix, we observe that the austenite showed higher content of iron than the ferrite after solubilization, but lower chromium content than the ferritic phase as OLASEINDE, O.A. et.all. (2012). The kinetics of the phase chromium rich precipitation also affects the properties of the elements in the oxide layer as study by MANDRINO, D. et. all. (2010).

On the other hand there is seen that the dissolution of metal ions $\mathrm{Fe}^{3+}$ and $\mathrm{Cr}^{3+}$ to give rise to a loss of mass during the anodic oxide film growth, However, these metal ions $\mathrm{Fe}^{3+}$ and $\mathrm{Cr}^{3+}$ are incorporated into the film and dissolved in solution, thus changing the molar fraction of these elements in the film.

Thus, there is an oxidized iron increases and the oxidized chromium decreases and an increase in the $\mathrm{Fe}_{3} \mathrm{O}_{4}$ and $\mathrm{Cr}_{2} \mathrm{O}_{3}$ oxides content and a decrease of $\mathrm{Fe}_{2} \mathrm{O}_{3}$ and $\mathrm{CrO}_{3}$ oxides content for two DSS 2205, with lower and higher chromium content, that thermodynamically balance the levels of oxide films.

The depletion in the chromium oxide content in the surface oxide layer is related with the precipitation of the chromium rich phases, which decreased the corrosion resistance of the alloy according to FREDRIKSSON, W. et. all. (2012).

Table 1. The composition of DSS 2205 with higher and lower Cr content

\begin{tabular}{cccccccccc}
\hline Elements & $\mathbf{C r}$ & $\mathbf{N i}$ & $\mathbf{C}$ & $\mathbf{M n}$ & $\mathbf{S i}$ & $\mathbf{P}$ & $\mathbf{S}$ & $\mathbf{M o}$ & $\mathbf{N}$ \\
\hline & 22.6 & 5.38 & 0.024 & 1.57 & 0.35 & 0.013 & 0.008 & 2.58 & 0.13 \\
\cline { 2 - 10 } Content (\%) & 17.2 & 5.37 & 0.018 & 1.60 & 0.37 & 0.011 & 0.006 & 2.54 & 0.11 \\
\hline
\end{tabular}

Table 2. Composition of $\mathrm{Cr}$ and $\mathrm{Fe}$ in the ferrite and austenite phases in the solubilized samples

\begin{tabular}{|c|c|c|c|c|}
\hline \multirow{2}{*}{ DSS 2205 } & \multicolumn{2}{|c|}{ Higher Cr } & \multicolumn{2}{c|}{ Lower Cr } \\
\cline { 2 - 5 } & Austenite & Ferrite & Austenite & Ferrite \\
\hline $\mathrm{Cr}$ & 21,27 & 24,90 & 16.97 & 18.43 \\
\hline $\mathrm{Fe}$ & 67.82 & 65.69 & 72.78 & 72.32 \\
\hline
\end{tabular}

Table 3. Composition of the oxide layer and of each oxide presented in the oxide layer before and after anodic oxide film growth, analysed by XPS

\begin{tabular}{|l|c|c|c|c|}
\hline & \multicolumn{2}{|c|}{ Higher Cr } & \multicolumn{2}{c|}{ Lower $\mathrm{Cr}$} \\
\hline \multirow{3}{*}{ Oxide layer } & $\mathrm{Fe}_{\text {oxide }} /\left(\mathrm{Fe}_{\text {oxide }}+\mathrm{Cr}_{\text {oxide }}\right)$ & $0.47 / 0.55$ & $\mathrm{Fe}_{\text {oxide }} /\left(\mathrm{Fe}_{\text {oxide }}+\mathrm{Cr}_{\text {oxide }}\right)$ & $0.28 / 0.30$ \\
\cline { 2 - 5 } & $\mathrm{Cr}_{\text {oxide }} /\left(\mathrm{Cr}_{\text {oxide }}+\mathrm{Fe}_{\text {oxide }}\right)$ & $0.56 / 0.42$ & $\mathrm{Cr}_{\text {oxide }} /\left(\mathrm{Cr}_{\text {oxide }}+\mathrm{Fe}_{\text {oxide }}\right)$ & $0.29 / 0.25$ \\
\hline
\end{tabular}


Table 3 shows these analysed by XPS measurements for the alloy DSS 2205 lower and higher chromium content in the annealed heat treated conditions during $7000 \mathrm{~h}$ at $300^{\circ} \mathrm{C}$.

The results confirm that there is just the presence of iron and chromium oxides at the surface oxide layer, two types of iron oxide: $\mathrm{Fe}_{2} \mathrm{O}_{3}$ and $\mathrm{Fe}_{3} \mathrm{O}_{4}$; and two types of chromium oxide: $\mathrm{Cr}_{2} \mathrm{O}_{3}$ and $\mathrm{CrO}_{3}$.

The annealing promotes the enrichment of iron oxide, and consequently the decrease in the chromium oxide content, in the oxide surface.The minimized chromium-depleted zones around precipitated phases after 7000 hours of aging which shows the presence of a larger amount of chromium in the passive film of the samples aged for 7000 hours according to MAY, J.E., et.all. (2010). The oxide layer formed on stainless steel surfaces is usually composed by mixed $\mathrm{Cr}-\mathrm{Fe}$ oxides, and after the ageing at $300^{\circ} \mathrm{C}$ appear important decrease in $\mathrm{Fe} / \mathrm{Cr}$ ratio as ABREU, C. M. et.all. (2008).

Figures 1 and 2 show that the oxide layers had their reduced concentrations of metal oxides as we increase the sputtering profile in the surface of the oxide layer according to NEUROHR, K.; et.all. (2011) formed in sample DSS 2205 with high and low $\mathrm{Cr}$ respectively aging for $7000 \mathrm{~h}$ at $300^{\circ} \mathrm{C}$.

Figure 3 shows the apparent microstructural characteristics, of the quantity of chromium of the DSS ageing at $300^{\circ} \mathrm{C}$ for $7000 \mathrm{~h}$ with higher and lower $\mathrm{Cr}$ content.

Figure 4 and 5 shows potentiodynamic curves for the sample with high and low chromium, where the passive film starts to form and grow similarly to both from a critical current density around $10^{-4} \mathrm{~A} / \mathrm{cm}^{2}$, rate of scan $10 \mathrm{mV} / \mathrm{s}$ and also for higher rates have higher current densities.

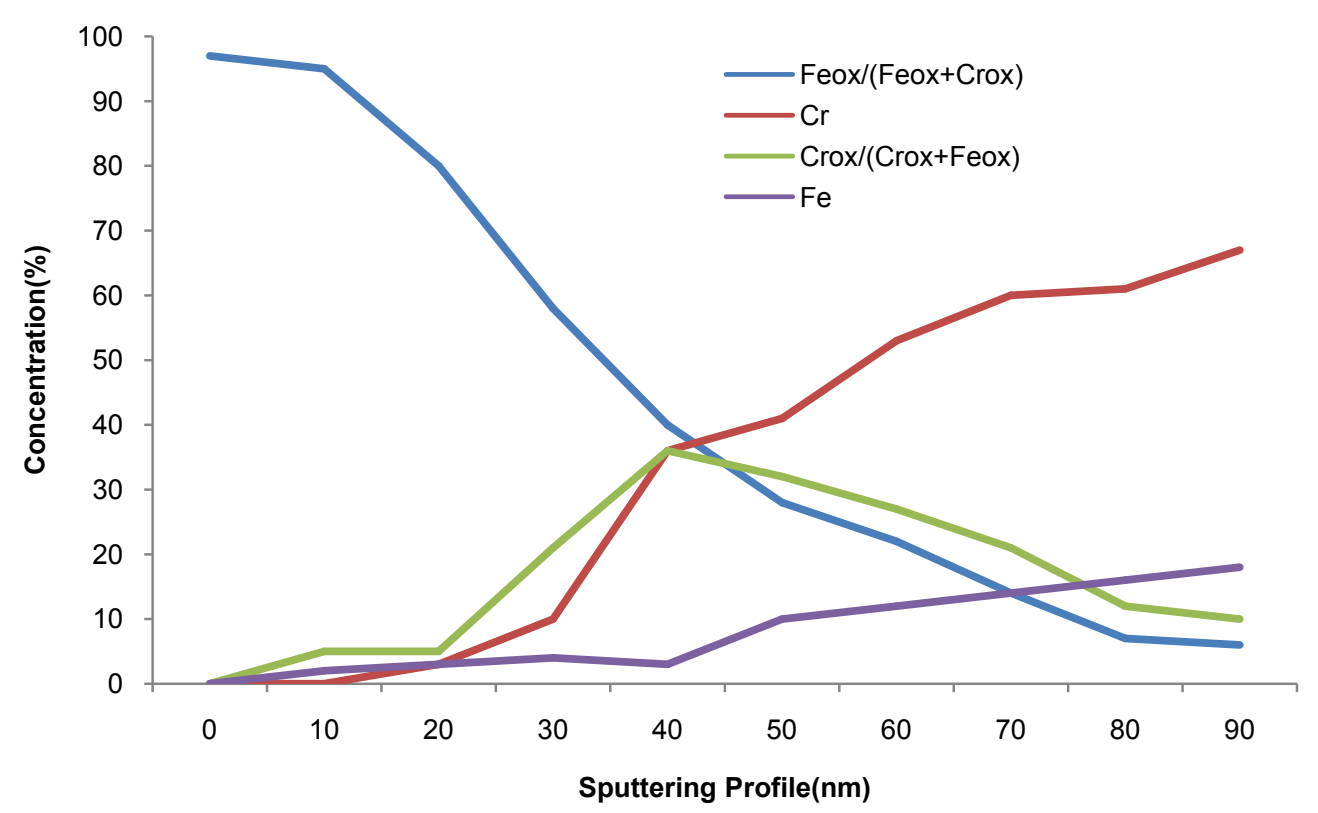

Figure 1. XPS depth profile of DSS 2205 higher $\mathrm{Cr}$ content oxidized at $300^{\circ} \mathrm{C}$ for $7000 \mathrm{~h}$

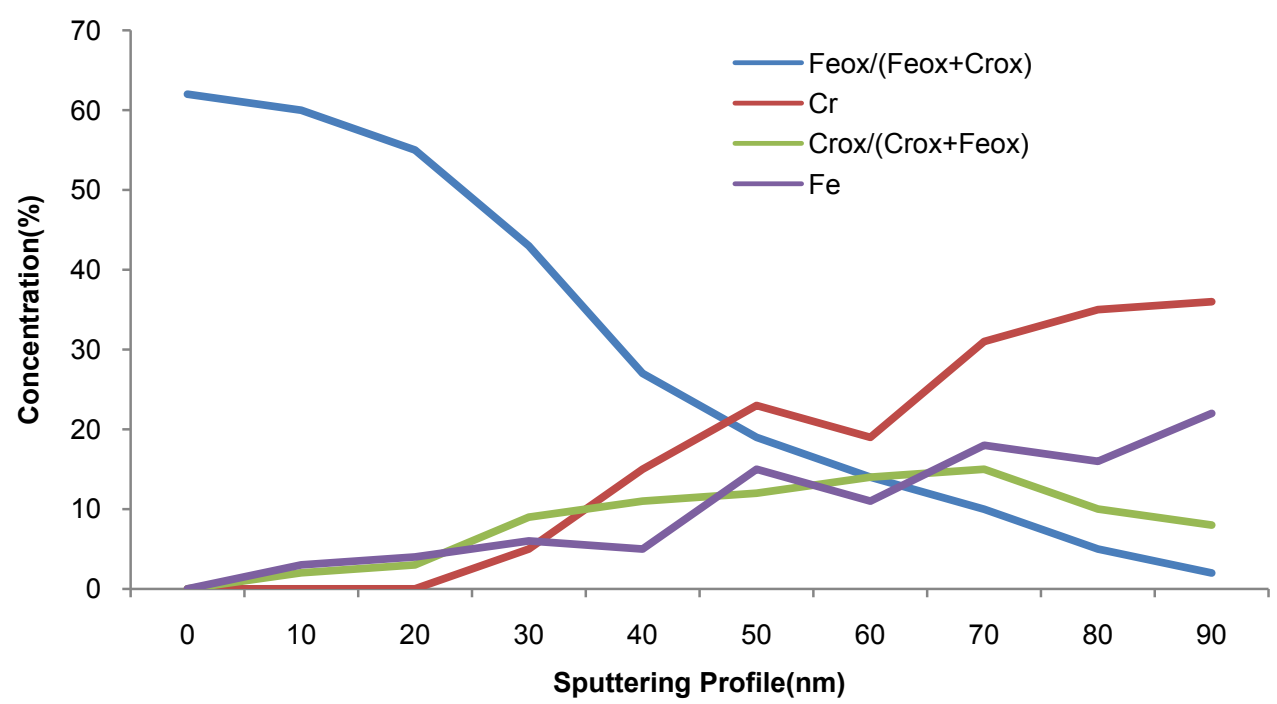

Figure 2. XPS depth profile of DSS 2205 lower $\mathrm{Cr}$ content oxidized at $300^{\circ} \mathrm{C}$ for $7000 \mathrm{~h}$ 

in DSS 2205 with Higher and Lower Chromium Content Due to Ageing for 7000 Hours at $300^{\circ} \mathrm{C}$

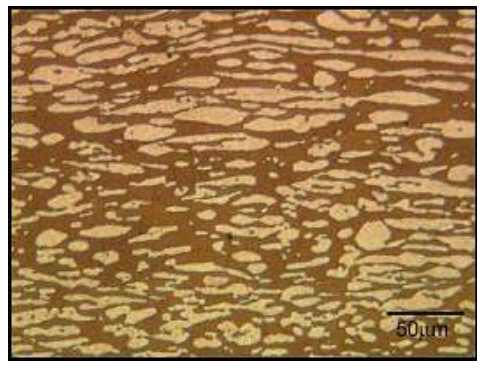

(a)

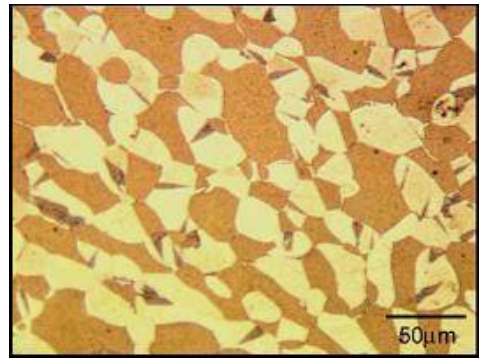

(b)

Figure 3. Micrographs of the ageing at $300^{\circ} \mathrm{C}$ for $7000 \mathrm{~h}$ samples with higher (a) and lower (b) $\mathrm{Cr}$ content. Etching: Behara II

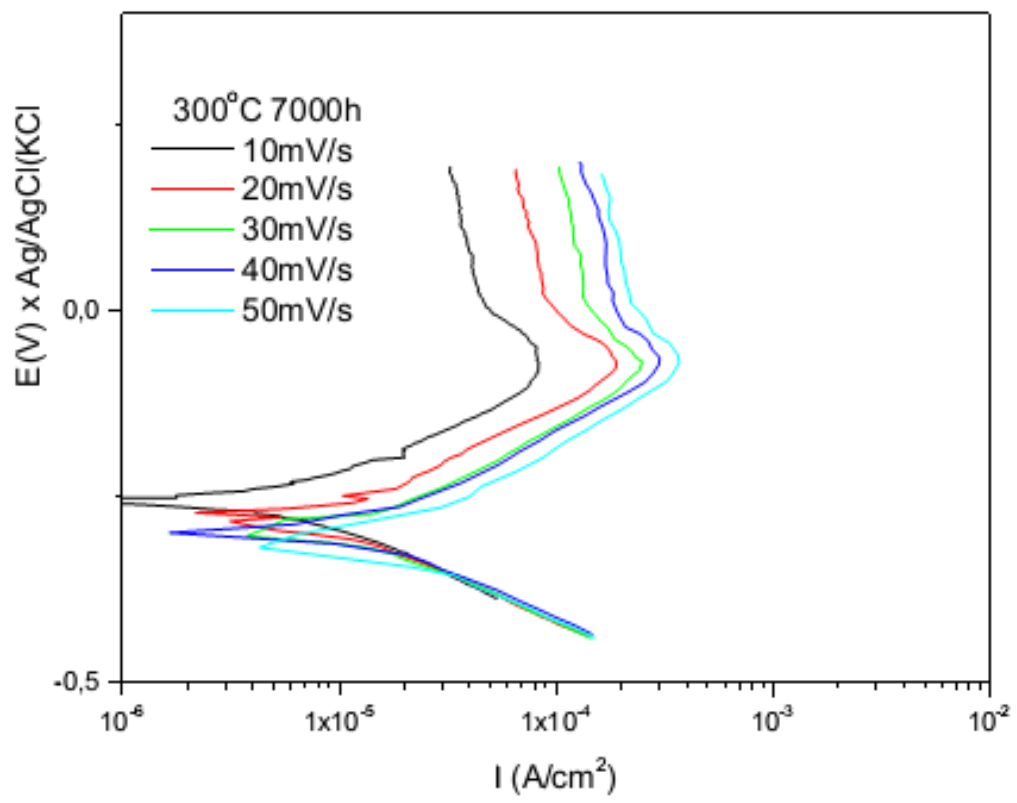

Figure 4. Anodic polarization curves of the sample with high content of $\mathrm{Cr}$ in different speeds scans; solution: $0.1 \mathrm{M} \mathrm{H}_{2} \mathrm{SO}_{4}$; $\mathrm{CE}=$ platinum; $\mathrm{ER}=$ $\mathrm{Ag} / \mathrm{AgCl}_{\text {saturated }}$

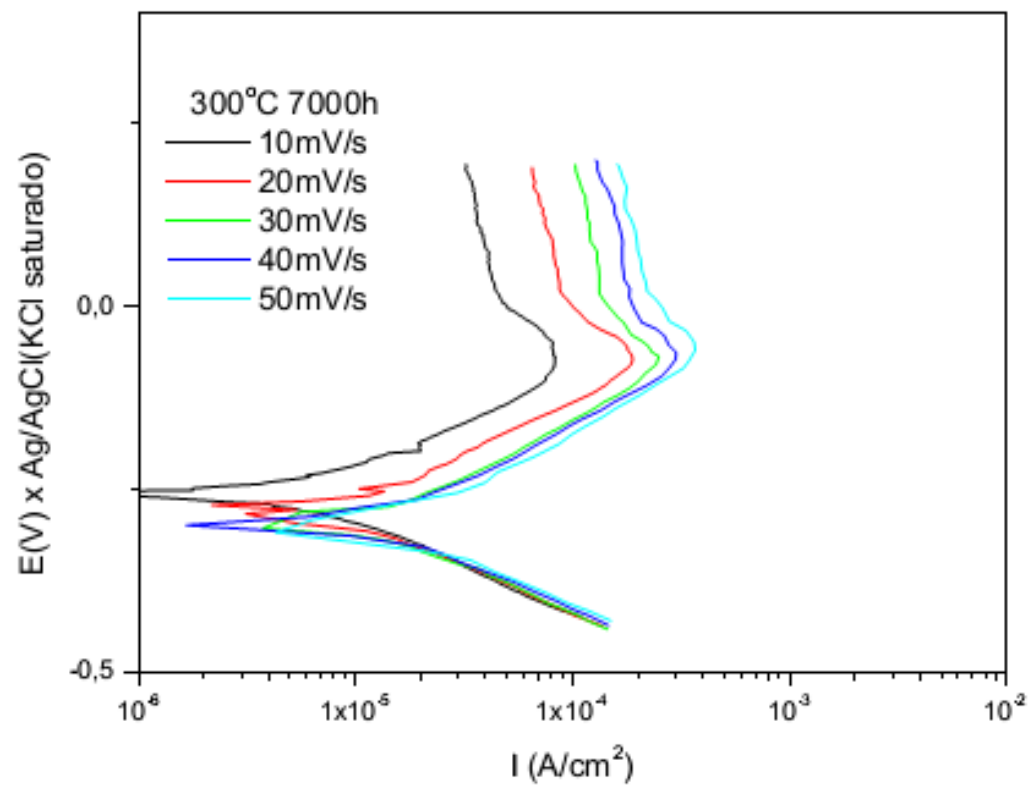

Figure 5. Anodic polarization curves of the sample with lower content of $\mathrm{Cr}$ in different speeds scans; solution: $0.1 \mathrm{M} \mathrm{H}_{2} \mathrm{SO} \mathrm{O}_{4} ; \mathrm{CE}=$ platinum; $\mathrm{ER}=$ $\mathrm{Ag} / \mathrm{AgCl}_{\text {saturated }}$ 
Note that the peak active passive transition (primary passivation potential) appears in $-100 \mathrm{mV}$ for both samples high and low $\mathrm{Cr}$ and that for all scan rates of potential trend is also increasing the density of their current.

\section{Conclusions}

The oxidation of DSS 2205 leads to two important factors that influenced the growth and composition of the oxide film that were formed at temperature $300^{\circ} \mathrm{C}$, therefore lead to segregation of the chromium to the surface and a sequential process of oxidation.

Thus, there was a possible enrichment of chromium oxide at the interface oxide/metal base and that this enrichment of caused a debilitation of chromium in the metal surface.

Therefore this study showed results about the behavior of the DSS 2205 with higher and lower $\mathrm{Cr}$ content and that the annealing at $300^{\circ} \mathrm{C}$ for longer times $(7000 \mathrm{~h})$ promotes the enrichment of iron oxide, and consequently the decrease in the chromium oxide content, in the oxide surface of both the DSS 2205.

However, with the ageing at $7000 \mathrm{~h}$ the $\mathrm{Cr}$ content in the passive oxide increase due to the high amount this metal in ferrite, which will decrease in the surface of the oxide layer due to the chemical potential of chromium in the phases of the structure.

The XPS results showed that there was a clearly and significant reversal of values in the chromium and iron oxides content in the surface oxide film analysed, but the reverse depth profile analysis made it possible to compare the measured and the calculated composition depth profile of electrodeposited multilayers by ageing.

\section{ACKNOWLEDGMENTS}

This study was possible through of the performed Laboratory Corrosion UFSCAR - Materials Department, which is undoubtedly a center of excellence and reference in the world.

\section{REFERENCES}

[1] ASTEMAN, H.; SEGERDAHL, K.; SVENSSON, J. E. ; JOHANSSON, L. G.; HALVARSSON, M. and TANG, J.E. (2004) In: Oxidation of stainless steel in $\mathrm{H}_{2} \mathrm{O} / \mathrm{O}^{-2}$ environments - Role of chromium evaporation, Materials Science Forum, 461-464:775-782.

[2] VESEL, A.; DRENIK, A.; MOZETIC, M.; ZALAR, A.;
BALAT-PICHELIN, M. and BELE, M. (2007) In: AES Investigation of the stainless steel surface oxidized in plasma; Vacuum, 82(2):228-231.

[3] KOCIJAN, A., DONIK, C. and JENKO, M.; (2009) The Electrochemical Study of Duplex Stainless Steel in Chloride Solutions. Materials and Technology; 43(1):39.

[4] (a) DONIK, C.; KOCIJAN, A.; PAULIN, I. and JENKO, M.; (2009) The oxidation of duplex stainless steel at moderately elevated temperatures. Materials and Technology; 43(3):137-142.

[5] (b) DONIK, Č.; KOCIJAN, A.; GRANT, J.T.; JENKO, M.; DRENIK, A. and PIHLAR, B.(2009) XPS Study of duplex stainless steel oxidized by oxygen atoms. Corrosion Science, 51(4): 827-832.

[6] GRANROTH, S., OLOVSSON, W., HOLMSTRÖM, E., KNUT, R., GORGOI, M., SVENSSON,S. and KARIS, O. (2011) Understanding interface properties from high kinetic energy photoelectron spectroscopy and first principles theory Journal of Electron Spectroscopy and Related Phenomena, 183(1-3):80-93.

[7] KOCIJAN, A., DONIK, C. and JENKO, M.; (2009) The Electrochemical Study of Duplex Stainless Steel in Chloride Solutions. Materials and Technology; 43(1):39.

[8] OLASEINDE, O.A.; MERWE, J.W.; CORNISH, L.A.; CHOWN, L.H. and OLUBAMBI, P.A.; (2012) Electrochemical studies of Fe-21Cr-1Ni duplex stainless steels with $0.15 \%$ ruthenium at different temperatures. The Journal of the Southern African Institute of Mining and Metallurgy; 7A:535 -538

[9] MANDRINO, D.; DONIK, Č. and JENK, M. (2010) AES of thin oxide layers on a duplex stainless steel surface; Surface and Interface Analysis; Special Issue: ECASIA'09; 42(6-7):762-765.

[10] FREDRIKSSON, W., MALMGREN, S., GUSTAFSSON, T. , GORGOI, M., and EDSTRÖM, K., (2012) Full depth profile of passive films on $316 \mathrm{~L}$ stainless steel based on high resolution HAXPES in combination with ARXPS. Applied Surface Science 258(15):5790-5797.

[11] MAY, J.E., KURI, S.E., et. all; (2010) Effect of Thermal Aging Conditions on the Corrosion Properties and Hardness of a Duplex Stainless Steel. Materials Research; 13(4): 431-436.

[12] ABREU, C. M.; CRISTÓBAL, M. J.; NÓVOA, X. R.; PENA, G. and PÉREZ, M. C. (2008); Effect of chromium and nitrogen co-implantation on the characteristics of the passive layer developed on austenitic and duplex stainless steels. Surface and Interface Analysis; 40:294-298.

[13] NEURÓHR, K.; CSIK, A.; VAD, K.; BARTÓK, A.; MOLNÁR, G. and PÉTER, L.; (2011), Composition depth profile analysis of electrodeposited alloys and metal multilayers: the reverse approach; Journal Solid State Electrochemistry, 15:2523-2544. 